\title{
Comportamento ingestivo de novilhos sob suplementação em pastagens de capim-tanzânia sob diferentes intensidades de desfolhação' ${ }^{1}$
}

\section{Ricardo Pereira Manzano², Luiz Gustavo Nussio³, Fábio Prudêncio de Campos ${ }^{4}$, Mariana Peres Andreucci ${ }^{5}$, Rafael Zonzini Matthes da Costa}

\footnotetext{
${ }^{1}$ Parte da tese de doutorado do primeiro autor apresentada à USP/ESALQ - Financiado pela FAPESP

2 Doutor em Agronomia - Gerente de Produto - Ruminantes - Guabi Nutrição Animal, Campinas - SP.

${ }^{3}$ Departamento de Zootecnia - USP/ESALQ. Av Pádua Dias, 11, CEP: 13418-900 - Piracicaba - SP.

${ }^{4}$ Instituto de Zootecnia - CAPTA - Bovinos de leite. Rua Heitor Penteado, 56, CP. 60, Nova Odessa - SP

${ }^{5}$ Engenheiro Agrônomo formado pela USP/ESALQ.
}

RESUMO - Avaliou-se o efeito da intensidade de desfolhação da forragem e da suplementação protéica ou energética sobre o comportamento ingestivo de bovinos de corte. Foram utilizados oito novilhos canulados no rúmen, além dos animais traçadores para pastejar o capim-tanzânia (Panicum maximum Jacq.), em um sistema rotacionado com ciclos de pastejo de 33 dias de descanso e três dias de ocupação. As intensidades de desfolhação pré-definidas foram 1.000 e $4.000 \mathrm{~kg}$ matéria seca verde/ha (kg MSV/ha). Os novilhos foram distribuídos em dois quadrados latinos 4 x 4 e separados em dois grupos iguais nos piquetes, onde receberam os suplementos: $\mathrm{SS}=$ sem suplementação; $\mathrm{MMG}=2,24 \mathrm{~kg} / \mathrm{dia}$ de milho moído grosso, peneira de $8 \mathrm{~mm} ; \mathrm{MF}=2,24 \mathrm{~kg} /$ dia de milho floculado; $\mathrm{FS}=0,80 \mathrm{~kg} /$ dia de farelo de soja. Em cada período de ocupação, o comportamento ingestivo dos animais foi avaliado durante 24 horas consecutivas com observações a cada 5 minutos durante o dia e a cada 15 minutos à noite. A suplementação reduziu somente o tempo de ruminação. Os tempos em pastejo (470,6 vs 354,3 minutos/dia) e ruminação (408,5 vs 319,1 minutos/dia) aumentaram, enquanto o tempo em ócio reduziu nos animais mantidos em pastagem com intensidade de desfolhação de $1.000 \mathrm{~kg}$ MSV/ha em comparação àqueles mantidos na intensidade de desfolhação de $4.000 \mathrm{~kg}$ MSV/ha. Não houve efeito significativo da suplementação ou da interação MSV $\times$ suplementação sobre o comportamento ingestivo dos animais. A intensidade de desfolhação da forragem, em comparação à prática de suplementação, exerceu efeito mais acentuado sobre o comportamento ingestivo de bovinos em pastejo.

Palavras-chave: gramínea tropical, pastejo rotacionado, ruminantes, suplementação

\section{Chewing activity of supplemented steers in pasture of tanzaniagrass submitted to different defoliation intensity}

\begin{abstract}
The objective of this trial was to study the effect of forage defoliation intensity and energy or protein supplementation on chewing activity of beef cattle. Eight Nellore steers fitted with ruminal cannula were used in a rotational grazing system of tanzaniagrass (Panicum maximum Jacq.) with 33 days of resting and three days of grazing. Additional steers were allowed to access the pasture before those with ruminal cannula to maintain the green dry matter (GDM) residue at 1,000 or $4,000 \mathrm{~kg} / \mathrm{ha}$ as pre-planned. Steers were divided into two equal groups (1,000 or 4,000 $\mathrm{kg} \mathrm{GMD} / \mathrm{ha})$ in the paddock and within each group randomly assigned to treatments in two replicated $4 \times 4$ Latin squares. Treatments were: no supplement (control), $2.24 \mathrm{~kg} /$ day of coarsely ground corn (CGC), $2.24 \mathrm{~kg} / \mathrm{day}$ of steam flaked corn (SFC), or $0.8 \mathrm{~kg} / \mathrm{day}$ of soybean meal (SBM). In each of the three days of grazing, chewing activity was monitored during $24 \mathrm{~h}$ with observations registered every 5 minutes during the day and every 15 minutes at night. Only rumination time was reduced by supplementation. Time spent grazing (470.6 vs. 354.3 minutes/day) and ruminating (408.5 vs. 319.1 minutes/day) were increased while idle time was reduced on steers maintained residue at $1,000 \mathrm{~kg} \mathrm{GMD} / \mathrm{ha}$ compared to those at 4,000 $\mathrm{kg} \mathrm{GMD} / \mathrm{ha}$. Neither supplementation nor the interaction GDM residue $\mathrm{x}$ supplementation significantly affected the eating behavior of steers in this trial. Intensity of forage defoliation was more effective than suplementation on changing chewing activity of steers.
\end{abstract}

Key Words: bovine, rotational grazing, supplementation, tropical grass

\section{Introdução}

A produção de bovinos no Brasil baseia-se na utilização de pastagens tropicais, como reflexo das grandes áreas disponí- veis e da diversidade das espécies presentes. Apesar dessa característica da produção pecuária, o desempenho e a produtividade animal no país estão aquém das expectativas, tanto do ponto de vista biológico como do ponto de vista operacional. 
A maioria das pesquisas envolvendo o consumo de forragens tropicais não considera o comportamento ingestivo, e sim o desempenho dos animais dentro de cada sistema adotado. Hodgson (1990) e Cosgrove (1997) afirmaram que o desempenho animal depende da ingestão diária de energia digestível, que é o resultado da ingestão de MS multiplicado pela concentração de energia digestível da forragem. A quantidade de forragem ingerida diariamente é produto do tempo de pastejo e da taxa de ingestão da forragem. Essa taxa de ingestão é obtida pelo produto entre o número de bocados por minuto e a quantidade de forragem colhida por bocado. Nesse sentido, Hodgson (1990) relatou que, com a diminuição da massa ofertada, há concomitante redução na ingestão de MS por bocado, como reflexo da condição da pastagem.

Por outro lado, com a diminuição da oferta de forragem, verifica-se aumento na intensidade de pastejo. Humphreys (1991) descreveu a intensidade de desfolhação da planta forrageira como a porção de material colhido pelo animal ou como o material residual após o pastejo, portanto, fortemente influenciada pela massa de forragem no pré-pastejo, pela taxa de lotação e pela duração do período de pastejo. Assim, quanto maior a intensidade de desfolhação maior o tempo de pastejo e a taxa de bocados dos animais em gramíneas de clima temperado (Hodgson, 1990). Apesar disso, o consumo de forragem diminui à medida que reduzem o tamanho e a freqüência dos bocados. Portanto, a massa por bocado é, quase sempre, o principal determinante da quantidade de alimento consumida por um animal em pastejo (Cosgrove, 1997; Carvalho et al., 2001).

Hodgson (1990) afirmou que o tempo de pastejo é muito variável e depende da massa da forragem, podendo oscilar de 360 a 720 minutos/dia. Dificilmente, ovinos e bovinos ultrapassam o máximo de 720 minutos/dia na atividade de pastejo (Carvalho et al., 2001). Krysl \& Hess (1993) detectaram, em extensa revisão de literatura, que o tempo gasto na atividade de pastejo varia de 359 a 711 minutos/dia. O tempo de pastejo reflete a facilidade de apreensão e remoção da forragem da pastagem (Crowder \& Chheda, 1982). Tempos de pastejo superiores a 480 - 540 minutos/dia provavelmente indicam condições limitantes ao consumo (Hodgson, 1990). Cosgrove (1997) relatou que a diminuição na massa de forragem provoca aumento no tempo de pastejo, entretanto, em relvados adensados, onde a taxa de ingestão é dificultada, os animais podem reduzir o tempo de pastejo pela dificuldade de apreensão da forragem.

A estrutura e a composição botânica da pastagem podem ter efeito direto sobre a ingestão de forragem por animais em pastejo, independentemente da influência da composição química e do conteúdo de nutrientes da própria forragem (Hodgson, 1990). Resultados de estudos (Stobbs, 1973a,b) indicam que, em pastagens tropicais, a densidade volumétrica e a relação folha:colmo teriam importância mais relevante na determinação do comportamento ingestivo dos animais quando comparadas a pastagens de clima temperado. Fischer et al. (2002) mencionaram que o estudo do comportamento ingestivo de ruminantes propicia meios de adequar práticas de manejo para aumento da produtividade animal.

A suplementação protéica ou energética pode alterar o comportamento ingestivo de animais em pastejo, contudo, esse fato tem sido pouco avaliado. Alguns autores sugeriram a possibilidade de efeito sobre o tempo de pastejo de animais sob suplementação (Krysl \& Hess, 1993; Adams, 1995; Bonfim et al., 2000). Entretanto, é necessário avaliar outros fatores conjuntamente ao uso de suplementos para o completo entendimento do comportamento animal em pastejo.

Neste trabalho, avaliou-se o efeito da intensidade de desfolhação da forragem e da suplementação sobre o comportamento ingestivo de bovinos manejados em sistema de pastejo rotacionado.

\section{Material e Métodos}

O experimento foi conduzido na Fazenda Areão da USP/ ESALQ, localizada no municípiode Piracicaba-SP(2242’30"S; 47³8'30" W, 576 m), em uma área de 4,8 ha estabelecida com capim-tanzânia (Panicum maximum Jacq. cv. Tanzania), dividida em quatro blocos de $1.200 \mathrm{~m}^{2}$ e irrigada por um sistema de pivô central. Cada bloco foi subdividido em seis piquetes, três para cada intensidade de desfolhação (1.000 e $4.000 \mathrm{~kg} \mathrm{MSV/ha),} \mathrm{totalizando} 24$ subdivisões. Como método de pastejo, utilizou-se lotação rotacionada com ciclo de pastejo de 36 dias, três de ocupação e 33 de descanso. As taxas de lotação foram definidas considerando a massa de forragem pré-pastejo e o nível de massa seca residual definido (1.000 e $4.000 \mathrm{~kg} \mathrm{MSV/ha).}$

As estimativas de eficiência de colheita (IMC) de forragem foram realizadas por intermédio da relação entre a ingestão de MS (IMS) da forragem, o peso vivo e o tempo de pastejo dos animais. Para o cálculo da IMS da forragem, utilizou-se o seguinte modelo de Orskov (1988): IMS $=-0,822+0,0748(a+b)+40,7 c ;$ em que: IMS = ingestão de matéria seca; $\mathrm{kg} /$ dia; $\mathrm{a}+\mathrm{b}=$ degradabilidade potencial da MS, \%; c = taxa de degradação da MS, \%/h. Os valores "a+b" e "c" foram obtidos em concomitância ao experimento, utilizando-se os mesmos animais e concentrados e a mesma estrutura de divisão de piquetes, conforme metodologia descrita por Manzano (2002). 
A pastagem foi fertilizada com $334 \mathrm{~kg}$ de NPK da fórmula 24-04-24 ( $80 \mathrm{~kg}$ de N/ha para cada ciclo de pastejo), logo após a saída dos animais.

Foram utilizados oito novilhos Nelore canulados no rúmen, com peso vivo médio de $307 \mathrm{~kg}$, distribuídos em dois grupos iguais por período experimental, manejados em 12 piquetes, conforme a intensidade de desfolhação estabelecida. Utilizaram-se ainda animais traçadores para obtenção dos resíduos pós-pastejo definidos.

Avaliaram-se duas intensidades de desfolhação (1.000 e $4.000 \mathrm{~kg} \mathrm{MSV} / \mathrm{ha}$, maior e menor respectivamente) e quatro formas de suplementação aos animais em cada intensidade de desfolhação no período de verão. As formas de suplementação foram definidas como: $\mathrm{SS}=$ sem suplementação; $\mathrm{MMG}=2,24 \mathrm{~kg} / \mathrm{dia}$ de milho moído grosso em peneira com malha de $8 \mathrm{~mm} ; \mathrm{MF}=2,24 \mathrm{~kg} /$ dia de milho floculado (MF) (300 g/L); FS =0,8 kg/dia de farelo de soja. O milho floculado foi preparado pela empresa Rações Total Ltda., Três Corações - MG, aplicando-se processamento físico visando densidade final de $300 \mathrm{~g} / \mathrm{L}$.

Estimou-se a quantidade dos suplementos energéticos segundo expectativa de disponibilidade da fração nitrogenada proveniente da pastagem para garantir taxas de ganho de peso estimadas em 1,2 e 1,3 kg/dia, respectivamente, para os grupos sem suplementação e com suplementação diária de 2,24 kg de milho floculado (NRC, 1996). Nos animais sob suplementação com farelo de soja $(0,80 \mathrm{~kg} / \mathrm{dia})$, a adição desse suplemento foi realizada visando à estimulação da síntese de proteína microbiana, pela elevação da disponibilidade de proteína de maior taxa de degradação ruminal, a fim de atingir teores mais elevados de proteína dietética e amônia ruminal, com base na estimativa de ganho de 1,0 kg/dia (NRC, 1996).

Os suplementos foram fornecidos duas vezes ao dia (às 7 e 16h), em quantidades iguais, através da cânula ruminal para garantir a totalidade do suplemento oferecido. Os animais tiveram livre acesso à mistura mineral, disponibilizada em cochos apropriados posicionados em cada piquete de pastejo.

O período experimental teve duração de 50 dias (05/12/ 1999 a 24/01/2000), divididos em quatro períodos de 12 a 13 dias, com 8 a 9 dias de adaptação dos animais à dieta. A duração do período de adaptação variou de acordo com as condições meteorológicas predominantes que restringissem o manejo dos animais.

Os dados sobre o comportamento de pastejo dos oito animais foram obtidos por seis observadores treinados, que trabalharam em duplas, com turnos de observação de oito horas consecutivas. Os observadores foram posicionados em torre móvel, localizada a 3,5 m do nível do solo, com ângulo de visão de $360^{\circ}$. Cada animal foi identificado com marcas de tinta preta em várias partes do corpo.

As observações foram realizadas no $6^{0}$ e no $7 \underline{0}$ dia ou

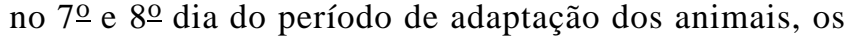
quais foram distribuídos em delineamento quadrado latino para conciliar os períodos de avaliação com um dos dias de ocupação dos piquetes, ou seja, as avaliações ocorreram em dias distintos, durante os três dias de ocupação. Assim, trabalhou-se, ao final, com a média dos resultados obtidos durante os dias de ocupação. As avaliações do comportamento ingestivo dos animais foram realizadas em 24 horas ininterruptas, a cada cinco minutos, das $12 \mathrm{~h}$ do primeiro dia às $11 \mathrm{~h} 55$ do dia seguinte. A observação dos animais foi realizada com auxílio de binóculo de visão diurna (Zenith $10 \times 50$ Field $5^{\circ}$ ) durante o período de iluminação solar e, à noite, em intervalos de 15 minutos utilizando-se binóculo de visão noturna (Night Vision Binoculars, modelo BN 356, Newcon, OH, USA). Como período noturno, considerou-se o intervalo das $20 \mathrm{~h}$ às $6 \mathrm{~h} 10$ do dia subseqüente. Durante as observações, foram anotados os tempos gastos nas atividades de pastejo, ruminação e ócio. O tempo gasto pelos animais com ingestão de água e sal mineral também foi considerado como ócio.

Os dados sobre a estrutura do dossel antes da entrada e após a saída dos animais dos piquetes foram obtidos de acordo com metodologia descrita por Penati (2002). A porcentagem de folhas foi obtida pela relação entre a massa seca de folhas e a massa seca verde do capim.

Utilizou-se o delineamento em quadrado latino 4 x 4 duplo, com um quadrado latino para cada intensidade de desfolhação, adotando-se o nível de significância de 5\% para detectar diferença estatística na análise de variância. Quando a análise detectou efeito significativo da suplementação sobre o comportamento de pastejo, as médias foram comparadas por meio dos seguintes contrastes: 1) SS vs MMG+MF+FS; 2) FS vs MMG+MF; 3) $M M G$ vs MF; 4) SS vs MMG+MF; 5) $S$ vs FS.

Para análise da variância, utilizou-se o procedimento GLM do programa SAS (1991) aplicando-se o teste Tukey para obtenção das médias. Como não houve interação intensidade de desfolhação $\times$ suplementos, optou-se pela eliminação dessa fonte de variação do modelo.

\section{Resultados e Discussão}

Os valores obtidos para os tempos de pastejo em cada intensidade de desfolhação (Figura 1) estão dentro da amplitude de valores típicos sugerida por Hodgson (1990) 


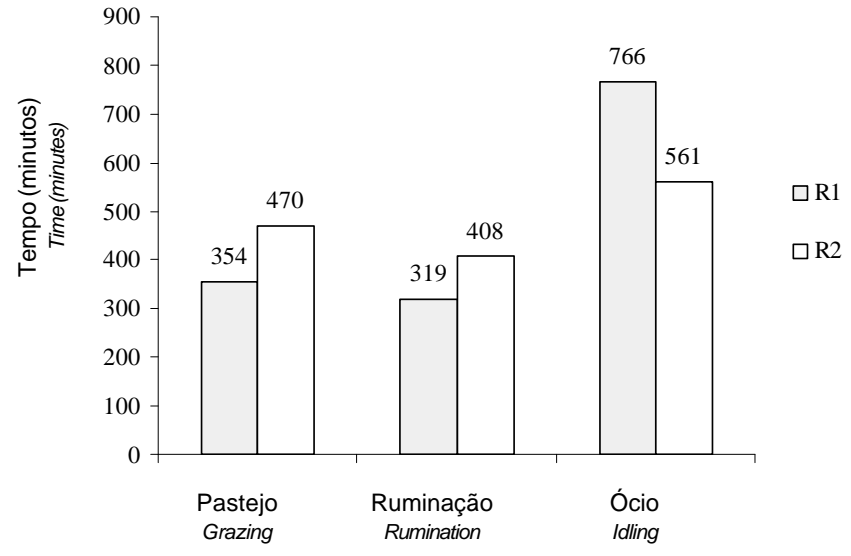

$\mathrm{R} 1$ = maior intensidade de desfolhação (1.000 kg MSV/ha) $\mathrm{R} 2$ = menor intensidade de desfolhação (4.000 kg MSV/ha)

$R 1$ = high defoliation intensity $(1,000 \mathrm{~kg}$ GDM/ha)

$R 2=$ low defoliation intensity $(4,000 \mathrm{~kg} \mathrm{GDM} / \mathrm{ha})$

Figura 1 - Tempos de pastejo, ruminação e ócio de novilhos sob suplementação protéica ou energética mantidos em pastejo de capim-tanzânia (Panicum maximum Jacq.) rotacionado em duas intensidade de desfolhação.

Figure 1 - Time spent grazing, ruminating, and idling in beef steers in a rotational grazing of tanzaniagrass submitted to two defoliation intensities.

e Krysl \& Hess (1993), de 359 a 720 minutos/dia. Houve efeito significativo da intensidade de desfolhação sobre o tempo de pastejo $(\mathrm{P}<0,05)$. Os tempos de pastejo e de ruminação foram maiores na menor (4.000 kg MSV/ha)intensidade de desfolhação, porém, o tempo de ócio foi maior para os animais mantidos em pastagem com maior $(1.000 \mathrm{~kg}$ MSV/ha) intensidade de desfolhação (Figura 1). Esse resultado indica que a estrutura do dossel ou o resíduo nos últimos dias de pastejo dificultou a colheita de forragem pelos animais, o que está de acordo com a afirmativa de Hodgson (1990), que relatou efeito da estrutura e da composição botânica da pastagem sobre a ingestão de forragem por animais em pastejo. Contudo, Gekara et al. (2001) observaram aumento no tempo de pastejo em resposta à redução na altura do dossel e, conseqüentemente, à menor quantidade de massa seca de forragem no pré-pastejo.

Nesse contexto, a maior porcentagem e quantidade de colmos na massa seca verde de forragem, expressa pela maior relação haste:folha, ou pela relação percentual entre MSV e MSF, na menor (4.000 kg MSV/ha) intensidade de desfolhação (Tabela 1), que resultou, provavelmente, em maior dificuldade de apreensão e menor valor nutritivo da forragem. Nesse sentido, o manejo da pastagem visando manter a massa seca residual próxima dos $4.000 \mathrm{~kg} / \mathrm{ha}$ pode resultar em maiores proporções e quantidades de hastes que poderão comprometer os demais ciclos de pastejo, justamente pelo acúmulo de hastes remanescentes que dificultarão o consumo pelos animais nos ciclos posteriores.

Outro fator que pode ter condicionado ao maior tempo de pastejo dos animais na maior ( $4.000 \mathrm{~kg} \mathrm{MSV} / \mathrm{ha}$ ) intensidade de desfolhação (Figura 1) está relacionado à maior disponibilidade de massa de forragem no pré-pastejo (Tabela 1). Esse resultado, no entanto, contraria as observações obtidas por Hodson (1990), que, em gramíneas de clima temperado, detectou que o tempo de pastejo e a taxa de bocado aumentaram conforme a intensidade de desfolhação e que, à medida que aumentaram a altura do dossel forrageiro e a massa de forragem, houve diminuição no tempo de pastejo.

No entanto, as gramíneas tropicais de alto potencial produtivo podem atingir alturas muito maiores que as de clima temperado. Nesse contexto, Silva \& Sarmento (2003) mencionaram que, em condições de ofertas generosas de gramíneas tropicais, ou seja, com a altura de dossel muito elevado, haveria maior tempo gasto em movimentos mandibulares de manipulação e mastigação que de bocados de apreensão de forragem. Esses autores notaram também uma provável participação ativa de fatores não-nutricionais na regulação da ingestão dos animais, decorrente desse tempo de manipulação e mastigação da forragem apreendida em bocados maiores. A conseqüência direta para o animal em pastejo seria sua grande dependência da disponibilidade de tempo para que níveis consideráveis de consumo pudessem ser efetivamente atingidos para a realização de metas elevadas de desempenho animal. Nesse sentido, os animais necessitariam de mais tempo para consumir essa gramínea de elevada altura do dossel forrageiro. Esse fato aponta o tempo de pastejo como um dos mais sérios fatores limitantes à maximização do desempenho animal em condições de pastejo, mesmo em condições em que há oferta abundante de forragem de bom valor nutritivo.

O menor tempo de pastejo dos animais manejados na maior intensidade de desfolhação, $1.000 \mathrm{~kg}$ de MSV/ha (Tabela 1), e o conseqüente maior tempo de ócio (Figura 1) podem estar relacionados à maior porcentagem de folhas, que foi de $66 \%$, obtida pela relação da MSF pela MSV da forragem no pré-pastejo, em comparação à menor intensidade de desfolhação, $4.000 \mathrm{~kg} \mathrm{MSV} / \mathrm{ha} \mathrm{(57 \% )} \mathrm{(Tabela} \mathrm{1),}$ e à elevada pressão de pastejo na pastagem com resíduo de $1.000 \mathrm{~kg}$ de MSV/ha. Entretanto, Ackerman et al. (1998) observaram que o aumento na taxa de lotação e, conseqüentemente, na intensidade de desfolhação resultou em acréscimo de 522 para 609 minutos/dia no tempo de pastejo de novilhos.

Segundo Cosgrove (1997), em relvados com alturas intensamente reduzidas pode haver diminuição no tempo 
de pastejo, visto que a taxa de ingestão é dificultada. Esse fato foi observado também por Chacon \& Stobbs (1976), ao avaliarem o tempo de pastejo de vacas em pastagens de Setaria anceps cv. Kazungula. Segundo esses autores, a redução do tempo de pastejo em pastagens com baixa disponibilidade de massa de forragem poderia ser explicada pela relutância dos animais em selecionar pequena quantidade de folhas em meio às hastes e às porções contaminadas por dejetos. Situação semelhante foi observada neste experimento, em que, na maior intensidade de desfolhação, a massa seca verde de forragem e a massa seca de folhas foram de 3.841 e $2.557 \mathrm{~kg} / \mathrm{ha}$, respectivamente, antes da entrada dos animais, sendo reduzidas para apenas 1.190 e $349 \mathrm{~kg} / \mathrm{ha}$, respectivamente, após a saída dos animais (Tabela 1). A relação entre essas variáveis (MSV e MSF) resultou em menor porcentagem de folhas residuais, na maior intensidade de desfolhação ( $29 \%$ vs $35 \%$ na menor intensidade de desfolhação), um indício da eficiência de colheita na maior intensidade de desfolhação $(1.000 \mathrm{~kg} / \mathrm{MSV} / \mathrm{ha})$ após 72 horas de ocupação do piquete. Contudo, a reduzida porcentagem de folhas no resíduo pode ter dificultado a seleção e apreensão da forragem pelos animais, fato confirmado pelo aumento da relação haste:folha na maior intensidade de desfolhação (Tabela 1), embora não tenha sido suficiente para aumentar o tempo de pastejo.

Outra possível explicação para a redução no tempo de pastejo dos animais submetidos à maior intensidade de desfolhação refere-se aos relatos de Jamieson \& Hodgson (1979), que observaram redução no tempo de pastejo em sistemas de pastejo rotacionado, em que a baixa produção de massa de forragem poderia determinar alteração comportamental nos animais. Nesses casos, os animais seriam, possivelmente, condicionados a ponderar entre a dificuldade de apreensão da forragem ao final do pastejo e a perspectiva de serem removidos a um novo piquete com maior quantidade de massa de forragem. Neste experimento, no último dia de ocupação dos piquetes, os animais posicionavam-se próximos às porteiras, à espera da mudança para novos piquetes, fato que reforça a idéia e a importância da avaliação pontual do dia de ocupação.

Os tempos de pastejo gastos pelos animais mantidos nos piquetes com menor intensidade desfolhação $(4.000 \mathrm{~kg}$ $\mathrm{MSV} / \mathrm{ha}$ ) foram próximos (Tabela 2) aos observados por Adams (1985) em gramíneas de clima temperado, de 438 e 540 minutos/dia para animais sob suplementação e 504 minutos/dia para o grupo sem suplementação.

Não houve efeito significativo $(\mathrm{P}>0,05)$ da suplementação sobre o tempo de pastejo (Tabela 2), fato constatado
Tabela 1 - Valores médios de massa seca verde de forragem (MSV), massa seca de folhas (MSF) e relação haste:folha no dossel antes e após o pastejo nas duas intensidades de desfolhação pré-definidas

Table 1 - Mean values of green DM (GDM), leaf DM (LDM) and stem:leaf ratio before and after grazing in two defoliation intensities

Intensidade de desfolhação (kg MSV/ha) Defoliation intensities ( $\mathrm{kg}$ GDM/ha)

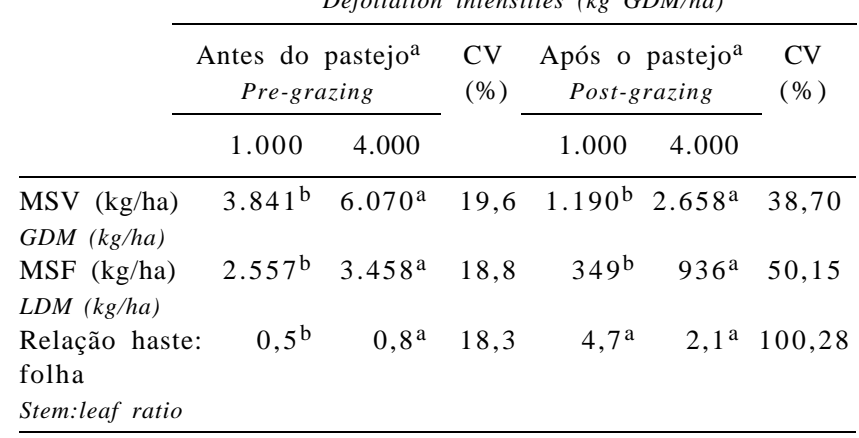

a Letras diferentes na mesma linha diferem $(P<0,05)$ entre si pelo teste Tukey.

a Different letters in the same row differ $(P<0.05$ by Tukey test).

também por Bonfim et al. (2000), que, ao avaliarem o efeito de quatro doses de suplemento concentrado em pastagens tropicais diferidas no período de inverno $(0,6 ; 0,9 ; 1,2$ e $1,5 \%$ do PV), verificaram valores de 315 a 386 minutos/dia.

O tempo de pastejo dos animais que não receberam suplemento (Tabela 2) foi semelhante aos 511 minutos/dia obtidos por Euclides et al. (1999) em pesquisa com novilhos Nelore pastejando capins colonião, tobiatã e tanzânia manejados sob lotação contínua no verão.

A ausência de efeito no tempo de pastejo mediante o fornecimento de suplemento aos animais (Tabela 2) é explicada, provavelmente, pela redução na taxa ou no tamanho de bocado. Nesse sentido, Krysl \& Hess (1993) demonstraram que, em algumas situações, os animais que recebem suplementação não reduzem o tempo de pastejo, e sim a intensidade de pastejo. Esses autores afirmaram que o pastejo intenso muitas vezes é substituído pelo exploratório. Segundo Barton et al. (1992), o pastejo intenso caracteriza-se por vários bocados na mesma touceira, sem o animal se mover, ao passo que o pastejo exploratório é caracterizado pela busca freqüente de novos sítios de pastejo, com poucos bocados a cada novo local. Contudo, neste ensaio, não foram avaliadas as formas de pastejo.

Krysl \& Hess (1993), em extensa revisão sobre o efeito da suplementação sobre o comportamento de pastejo de bovinos, observaram que geralmente a utilização de grãos (amido) como suplemento reduz o tempo de pastejo. Bodine et al. (2000) também verificaram, em pastagem de clima temperado, redução no tempo de pastejo de bovinos recebendo suplemento à base de milho na proporção de 
1,3\% do PV, exclusivamente ou misturado ao farelo de soja. No experimento realizado por esses autores, a massa seca de forragem no pré-pastejo variou entre 3.654 e $4.353 \mathrm{~kg}$ de MS/ha.

Gekara et al. (2001) também avaliaram o efeito da suplementação ( $0 ; 3,2$ e 6,4 kg/vaca/dia) sobre o comportamento de vacas de corte em pastejo e constataram que não houve diferença significativa entre o grupo controle e a média dos grupos que receberam suplemento, embora os autores tenham observado tendência $(\mathrm{P}=0,0528)$ de redução no tempo de pastejo pelos animais que receberam quantidades maiores de suplemento. Esses autores avaliaram duas intensidades de desfolhação e não constataram efeitos significativos da interação intensidade de desfolhação $\times$ quantidade de suplemento. Fato similar ocorreu neste experimento (Tabela 2) quando avaliados os contrastes pré-estabelecidos.

Ao calcular a eficiência de colheita ( $\mathrm{g}$ de MS de forragem $/ \mathrm{kg}$ PV/minutos de pastejo) dos animais submetidos aos dois resíduos pós-pastejo, observou-se que, apesar de os animais mantidos no piquete com massa residual de $1.000 \mathrm{~kg} \mathrm{MSV} / \mathrm{ha}$ terem reduzido o tempo de pastejo, a eficiência média de colheita foi superior $(0,058$ vs $0,046 \mathrm{~g}$ de MS de forragem $/ \mathrm{kg} \mathrm{PV} /$ minuto de pastejo, respectivamente) em comparação à obtida na menor intensidade de defolhação (4.000 kg MSV/ha). Entretanto, esses valores médios não foram submetidos à análise estatística. Essa maior eficiência de colheita dos animais submetidos à maior intensidade de desfolhação poderia ser explicada pela maior proporção de folhas na composição da forragem, o que provavelmente interferiu no resultado médio ao final dos três dias de ocupação. A maior eficiência de pastejo e os menores tempos de pastejo registrados para os animais em pastagem com maior intensidade de desfolhação (1.000 kg MSV/ha) poderiam reduzir o custo energético para realização do pastejo e permitiriam atenuar possíveis diferenças de desempenho causadas pela menor ingestão de MS da forragem, o que está de acordo com relatos de Barton et al. (1992) e Krysl \& Hess (1993).

Os tempos de ruminação e ócio (Figura 1; Tabela 2) foram influenciados pelas intensidades de desfolhação. Houve redução no tempo de ruminação e aumento no tempo em ócio $(\mathrm{P}<0,05)$ quando os animais foram expostos

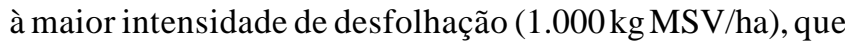
apresentava a menor disponibilidade de massa seca verde (Tabela 1). Isso pode ser explicado pelo menor tempo de pastejo observado nos animais que pastejaram até atingir a intensidade de desfolhação de $1.000 \mathrm{~kg} \mathrm{MS} / \mathrm{ha}$.

A suplementação reduziu $(\mathrm{P}<0,05)$ o tempo de ruminação (Tabela 2), entretanto, não houve interação suplementação $\times$ intensidade de desfolhação $(P=0,1162)$. O efeito de diluição causado pelo fornecimento do concentrado sobre o consumo de FDN provavelmente reduziu o tempo de ruminação dos animais que receberam suplemento. Não houve efeito significativo do tipo de suplemento ( $\mathrm{P}>0,05)$ sobre o tempo de ruminação (Tabela 2 ).

Adams (1985) não observou diferença entre os tempos de ruminação de bovinos de corte sob suplementação com milho e daqueles sem suplementação. O tempo de ruminação obtido na menor intensidade de desfolhação $(4.000 \mathrm{~kg}$ MSV/ha) (Tabela 2 e Figura 1) foi semelhante ao obtido por esse autor, de 420 minutos/dia. Entretanto, a quantidade de suplemento à base de milho fornecida aos animais em pastejo teve efeito significativo (de redução) do tempo de ruminação avaliado nos contrastes 1,4 e 5 (Tabela 2). Essa observação corrobora os relatos de Difante et al. (2001),

Tabela 2 - Tempos de pastejo, ruminação e ócio (minutos/dia) provenientes de novilhos em pastejo rotacionado de capim-tanzânia (Panicum maximum Jacq.) recebendo suplementação protéica ou energética

Table 2 - Mean values of time spent grazing, ruminating and idling in beef steers in a rotational grazing of tanzaniagrass fed with protein or energy supplements

\begin{tabular}{|c|c|c|c|c|c|c|c|c|c|c|}
\hline & \multicolumn{4}{|c|}{$\begin{array}{l}\text { Suplemento }^{\mathrm{a}} \\
\text { Supplement }\end{array}$} & \multirow[t]{2}{*}{$\begin{array}{c}\mathrm{EPM}^{\mathrm{b}} \\
S E M\end{array}$} & \multicolumn{5}{|c|}{$\begin{array}{c}\text { Contrastes }^{\mathrm{c}}(\mathrm{P}<) \\
\text { Contrasts }\end{array}$} \\
\hline & $\begin{array}{c}\text { SS } \\
\text { Control }\end{array}$ & $\begin{array}{c}\mathrm{MMG} \\
C G C\end{array}$ & $\begin{array}{l}\mathrm{MF} \\
S F C\end{array}$ & $\begin{array}{c}\mathrm{FS} \\
S B M\end{array}$ & & 1 & 2 & 3 & 4 & 5 \\
\hline $\begin{array}{l}\text { Tempo de pastejo } \\
\text { Grazing time }\end{array}$ & 414 & 430 & 391 & 416 & 19,2 & 0,9583 & 0,8752 & 0,3213 & 0,9190 & 0,9617 \\
\hline $\begin{array}{l}\text { Tempo de ruminação } \\
\text { Rumination time }\end{array}$ & 410 & 347 & 353 & 345 & 11,8 & 0,0060 & 0,8101 & 0,7948 & 0,0102 & 0,0148 \\
\hline $\begin{array}{l}\text { Tempo em ócio } \\
\text { Idle time }\end{array}$ & 616 & 662 & 696 & 679 & 24,9 & 0,1414 & 1,0000 & 0,5083 & 0,1640 & 0,2243 \\
\hline
\end{tabular}

a $\mathrm{SS}=$ sem suplemento, $\mathrm{MMG}=2,0 \mathrm{~kg} \mathrm{MS}$ milho moído grosso; $\mathrm{MF}=2,0 \mathrm{~kg}$ MS milho floculado; $\mathrm{FS}=0,8 \mathrm{~kg} \mathrm{MS}$ farelo de soja

b EPM = erro-padrão da média.

c 1 = SS vs MMG+MF+FS; 2 =MMG+MF vs FS; 3 = MMG vs MF; 4 = SS vs MMG+MF, $5=$ SS vs FS

a Control $=$ no supplement, $C G C=2.0 \mathrm{~kg}$ DM of coarsely ground corn; $S F C=2.0 \mathrm{~kg}$ DM of steam flaked corn; $S B M=0.8 \mathrm{~kg} D M$ of soybean meal

b $S E M=$ standard error of the mean.

c $1=$ Control vs. $C G C+S F C+S B M ; 2=C G C+S F C$ vs. SBM; $3=C G C$ vs. SFC.; $4=$ Control vs. CGC+SFC, $5=$ Control vs. SBM. 
que verificaram redução no tempo de ruminação e aumento no tempo em ócio nos animais que receberam concentrado na proporção de $0,8 \%$ do $P V$ em comparação aos que receberam quantidades menores ( $0,4 \%$ do PV de suplemento).

O tempo em ócio neste experimento não foi alterado (P>0,05) pela suplementação (Tabela 2), o que contraria as observações realizadas por Difante et al. (2001). Apenas o tempo de ruminação sofreu efeito significativo $(\mathrm{P}<0,05)$ da intensidade de desfolhação (Figura 1). Os tempos de ruminação e ócio (Figura 1 e Tabela 2) encontram-se abaixo e acima, respectivamente, dos valores reportados por Difante et al. (2001), que obtiveram tempos de ruminação de 514, 471 e 461 minutos/dia e tempos em ócio de 507, 555 e 612 minutos/dia em animais sem suplementação e sob suplementação com milho nas proporções de 0,4 e $0,8 \%$ do $\mathrm{PV}$, respectivamente.

O maior tempo em ócio dos animais em pastagens com massa residual de $1.000 \mathrm{~kg} \mathrm{MSV/ha} \mathrm{poderia} \mathrm{ser} \mathrm{explicado}$ pelos menores tempos de pastejo e ruminação (Figura $1 \mathrm{e}$ Tabela 2).

\section{Conclusões}

A maior intensidade de desfolhação do capim-tanzânia em sistema rotacionado diminui os tempos de pastejo e de ruminação, enquanto o tempo de ócio aumenta.

O uso de suplementação energética ou protéica não altera o tempo de pastejo e o tempo em ócio, mas diminui o de ruminação, em consequiência do menor consumo de componentes da parede celular (FDN), causado pelo fornecimento do concentrado. A massa seca de forragem disponível na pastagem exerce efeito mais acentuado sobre o comportamento ingestivo de bovinos em pastejo que a prática de suplementação.

\section{Agradecimento}

À Fundação de Amparo à Pesquisa do Estado de São Paulo (FAPESP), pela concessão da bolsa de estudos ao primeiro autor e pelo financiamento do projeto. Aos estagiários e alunos de Pós-graduação do Projeto Capim da USP/ESALQ, pela colaboração e pelo empenho na condução do experimento.

\section{Literatura Citada}

ACKERMAN, C.J.; PAISLEY, S.I.; PURVIS II, H.T. et al. Summer gains of heavy vs light weight steers grazing old world bluestem at three stocking rates. Journal of Animal Science, v.76, p.192, 1998 (suppl. 1).
ADAMS, D.C. Effect of time of supplementation on performance, forage intake and grazing behavior of yearling beef steers grazing Russian wild ryegrass in the fall. Journal of Animal Science, v.61, p.1037-1042, 1985.

BARTON, R.K.; KRYSL, L.J.; JUDKINS M.B. et al. Time of daily supplementation for steers grazing dormant intermediate wheatgrass pasture. Journal of Animal Science, v.70, p.547$554,1992$.

BODINE, T.N.; PURVIS II, H.T.; COX, D.A. [2000]. Effects of supplemental energy and degradable intake protein on grazing behavior, forage intake, digestion and performance of steers grazing winter forage: 2000 Animal Science Research Report. Disponível em: <htttp:// www.ansi.okstate.edu/research/2000rr/0.7htm.> Acesso em: 21/08/2001.

BONFIM, M.A.D.; REZENDE, C.A.P.; PAIVA, P.C.A. et al. Efeito do nível de concentrado no tempo de pastejo de novilhos holandês $x$ zebu suplementados a pasto na estação seca. In: REUNIÃO ANUAL DA SOCIEDADE BRASILEIRA DE ZOotecniA, 37., 2000, Viçosa, MG. Anais... Viçosa, MG: Sociedade Brasileira de Zootecnia, 2000. p.10.

CARVALHO, P.C.F.; RIBEIRO FILHO, H.M.N.; POLI, C.H.E.C. et al. Importância da estrutura da pastagem na ingestão e seleção de dietas pelo animal em pastejo. In: MATTOS, W.R.S. (Ed.). A produção animal na visão dos brasileiros. Piracicaba: Fundação de Estudos Agrários Luiz de Queiroz, 2001. p.853-871.

CHACON, E.; STOBBS, T.H. Influence of progressive defoliation of a grass sward on the eating behaviour of cattle. Australian Journal of Agricultural Research, v.27, p.709-727, 1976.

COSGROVE, G.P. Grazing behaviour and forage intake. In: INTERNATIONAL SYMPOSIUM ON ANIMAL PRODUCTION UNDER GRAZING, 1997, Viçosa, MG. Anais... Viçosa, MG: Unviersidade Federal de Viçosa, 1997. p.59-80.

CROWDER, L.V.; CHHEDA, H.R. Tropical grassland husbandry. New York: Longman Tropical Agricultural Series, 1982. 562p.

DIFANTE, G.S.; MARCHEZAN, E.; MARZARI, V. et al. Produção de novilhos de corte suplementados em pastagens de inverno, submetida a doses de adubação nitrogenada em áreas de várzea. In: REUNIÃO ANUAL DA SOCIEDADE BRASILEIRA DE ZOOTECNIA, 38., 2001, Piracicaba. Anais... Piracicaba: Sociedade Brasileira de Zootecnia, 2001. p.375-376.

EUCLIDES, V.P.B.; THIAGO, L.R.L.S.; MACEDO, M.C.M. et al. Consumo voluntário de forragem de três cultivares de Panicum maximum sob pastejo. Revista Brasileira de Zootecnia, v.28, p.1177-1185, 1999.

FISCHER, V.; MDESWYSEN, A.G.; DUTILLEUL, P. et al. Padrões da distribuição nictemeral do comportamento ingestivo diurno de vacas leiteiras, ao início e ao final da lactação, alimentadas com dieta à base de silagem de milho. Revista Brasileira de Zootecnia, v.31, p.2129-2138, 2002.

GEKARA, O.J.; PRIGGE, E.C.; BRYAN, W.B. et al. Influence of pasture sward height and concentrate supplementation on intake, digestibility, and grazing time of lactating beef cows. Journal of Animal Science, v.79, p.745-752, 2001.

HODGSON, J. Grazing management: science into practice. Essex: Longman, 1990. 203p.

JAMIESON, W.S.; HODGSON, J. The effect of daily herbage allowance and sward characteristics upon the ingestive behavior and herbage intake of calves under strip-grazing management. Grass and Forage Science, v.34, p.261, 1979.

KRYSL, L.J.; HESS, B.W. Influence of supplementation on behavior of grazing cattle. Journal of Animal Science, v.71, p.25462555, 1993.

MANZANO, R.P. Consumo, parâmetros ruminais e comportamento de bovinos de corte em pastejo de capim Tanzânia (Panicum maximum Jacq. cv. Tanzânia) suplementados com fontes de energia ou de proteína. Piracicaba, 2002. 160p. Tese (Doutorado em Ciência Animal e 
Pastagens) - Escola Superior de Agricultura "Luiz de Queiroz", 2002 .

NATIONAL RESEARCH COUNCIL - NRC. Nutrient requirements of beef cattle. 7.ed. Washington, D.C.: National Academy of Sciences, 1996. 242p.

ORSKOV, E.R. Nutrición proteica de los ruminantes. Zaragoza: Acribia, 1988. 178p.

PENATI, M.A. Estudo do desempenho animal e produção do capim Tanzânia (Panicum maximum Jacq.) em um sistema rotacionado de pastejo sob irrigação em três níveis de resíduo pós-pastejo. Piracicaba: Escola Superior de Agricultura "Luiz de Queiroz", 2002. 117p. Tese (Doutorado em Ciência Animal e Pastagens) - Escola Superior de Agricultura "Luiz de Queiroz", 2002.

STATISTICAL ANALYSIS SYSTEM - SAS. User's guide: statistics. 5.ed. Cary, 1991. 213p.

SILVA, S.C.; SARMENTO, D.O.L. Consumo de forragem sob condições de pastejo. In: REIS, R.A.; BERNADES, T.F.; SIQUEIRA, G.R. et al. (Eds.) Volumosos na produção de ruminantes - Valor alimentício de forragens. Jaboticabal: FUNEP, 2003. p.101-122.

STOBBS, T.H. The effect of plant structure on intake of tropical pastures. I. Variation in the bite size of grazing cattle. Australian Journal of Agricultural Research, v.24, p.809-819, 1973a.

STOBBS, T.H. The effect of plant structure on intake of tropical pastures. II. Differences in sward structure, nutritive value, and bite size of animals grazing Setaria anceps and Chloris gayana at various stages of growth. Australian Journal of Agricultural Research, v.24, p.821-829, 1973b. 